\title{
FEATURE ARTIGLES
}

\section{Education and the Impact of Computer Techlogy}

by Tom Rich

Once again, educators find themselves at a crossroads. Current advances in on schools. The educational system faces the prospect of a radical change to a
system that has remained relatively constant for more than 100 years. Before assessing the situation, it is useful to
briefly review what led to the current

In the past, education has gone through Formal schilint changes in technology. Formal schooling began using the oral must know or were engaged in Socratic The first revolution in education

writing. It allowed information to be precisely stored, but its potential was no universally applauded. Socrates warned
that "the discovery of writing will create forgetfulness in the learners' souls
because they will not use their memories because they will not use their memories characters and not remember themselves."

The second revolution in education was printing press. Before the advent of mas produced books education was onl available to the fortunate few who could get access to a very limited supply of
books and master teachers. With easily reproducible books, information became truly portable and accessible. It should
also be remembered that at the time of the invention of the printing press, all th information known to man could be stored in a small set of books

The third revolution in education photography. This gave us the ability to capture a representation of the real on film. With the further development of motion picture photography, education,
in a sense, came full circle. Originally education concerned itself with the rea
what could be touched felt or directly manipulated. The written word distance us from the real as it forced us to deal more with the subjective and abstract.
Photography brought us closer again to the real, or what appeared to be real. Today, we are in the midst of a fourth
revolution brought about by the advent 0 Tom Rich is the director of educationa services for the P.E.I. department education
AMTEC. what is often called the "new informatio puters with communications. Particularly significant, of course, is the impact of
microcomputers on schools. It is important to note the newness of this only 38 years old while the microcom puter has been with us for less than 1 years and readily accessible only for 7 .
The new information technologies inThe new information technologies in-
clude videodiscs, videotex, interactive elevision, communications satellites an other powerful communications devices
but it is only the computer that has actually penetrated the classroom to any grea
extent. Thus, it is helpful to look at why this has happened and the implications puter, for education.

Impact of Computers on Schools of television and other innovations have been widely experimented with the have in education has been mainly restricted to post-secondary institutions, business and industry. This arises both from the nature
of our school system and the costs of of our school system and the costs many of these new technologies. Many selves more to training applications be precisely identified. In addition, on lesson learned from the introduction of importance of content. Any technological ware (programs, if you will) it carries. Th production of quality software invariably lags several years behind the production
of hardware (equipment). Why then have computers had such dramatic impact on education? Althoug past several years, the computer is still one of the most expensive pieces of hardware that a school can purchase and many are needed to serve a school. In ada serious lack of good quality educational
software for computers.

Perhaps most significant, and over-
riding these points, is the fact that the introduction of computer technology education has been considerably different technology adopted by educators. This would appear to arise from four factors.
First, of course, is the radical impact that computers are having on the work force. next several years between 50 and 70 per- cent of all jobs will be computer related.
Thus, there is tremendous pressure from parents and employers to ensure that
education prepare students to deal with the use of this new technology in the is the fact that this pressure teach about and to use computers com as much from outside the education system as from within. We have probably never before seen a time when paren adopt a particular "machine" to use in instruction. Nor have we seen quite the sort of involvement of home and school associations and others in purchasin computers for schools as we do now.
The third factor is the reaction students to computers. A significant number of them seem tremendously excited and involved by computers. No other machine or concept has received their seeming ability to motivate and captivate students. Finally, those promoting computers
tivate ste change the educational system and th way we learn. Perhaps fuelled by the obvious interest of young people in com
puters, this has led to a common assumption that computers can and will chum the structure of education. This belief is complemented by the first factor mentioned, i.e., the obvious impact conputers are having on the workplace.
All of these factors, to a greater or lesse extent, revolve around the impact that the emergence of the "information society" having upon society. As stated by Masud
$(1980)$, the information society is based on the belief that "the production of information values and not material values mation and development of society (p. 29). The framework for this society is technology, which determines the furindustrial society the neam order. In the to amplify the physical labour of man. the information society the computer
serves to amplify the mental labour o

Much of business and industry, an more recently governments and parents have apparently accepted the inevitabilly
of these predictions and are now callin for the educational system to both make
use of and teach about computer technology. The schools have responded an in a few short years, the numbers of com
puters in schools have climbed from a $\begin{array}{ll}\text { handful to the point where at the end of } & \text { the de-skilling of certain types of jobs. } \\ \text { the last school year more than } 50 \% \text { of } & \text { Working on an assembly line may no }\end{array}$ in North computer (Becker, 1983 and Rich, 1983). se of Computers in Schools fat that educators have taken the heart is seen in the types of use con to puters are being put to in schools. In the United States, a major study of use of
computers conducted by Johns Hopkins University (Becker, 1983) revealed the ollowing use patterns. The percentages shown are the proportion of computers
used for the task listed. used for the task listed.

Introduction to computers

Programming instr

Introduction to computers
Drill and practice

Programming instruction
Tutoring for special needs

below $31 \%$. It should also be pointed were hat high schools were much more likely to have a computer $(85 \%)$ than elemenlucted in Canada by TV Ontario (Sharon1984) suggested much the same pattern of use and penetration although specific gures were not provided.

The "introduction of computers" us isted along with the programming in-
struction reflects the response of the struction reflects the response of the
schools to the demand to teach students something about computers. This forms he first, and by far still most common, use of computers in schools. It is based on hill be computer related. While, on he face of it, true this is a misleading dea. As pointed out by Menosky (1984)
hese jobs include everything from grocery store clerks using a bar code eader to a retailer selling video game carggested 30 million jobs that are com require related, the vast majority will puters. Rather, it appears that the actua number of jobs requiring specific "h-
lechnology" training will be small. Menosky further states that of the 20 occups, not one is in high-technology. The
jobs, such as janitors, nurses' aides, sales clerks, waitresses and waiters, etc. In lact, there is growing evidence that the mpact of computers on the workplace
may result in a polarization of skills and ability to monitor a machine and push button. There are also concerns that in technology will not create as many jobs as are displaced.

Thus, the impact of computers and workp of high technology on the than many be much more complex ltogether too simplistic to suinly it is the answer to a job in the future is to know how to operate or program a com puter. The need for those skills may be some. The less than anticipated by ticular, would seem to begram, in parparatively few students in the future. Thi is because computers are rapidly learnis to program themselves and because new generations of computers require les knowledge about computers than before. his is readly evident to anyone who has Macintosh computer. For the Lisa or business computer user the emphasis is on knowing how to apply the power of The

The second significant use of computers schools at present is in compute s typically still drill and practice activity and is most common in the elementary grades. This application of computers has oftware available. publishers have moved into the field and thstantial amounts of good software now becoming available.

The computer is being used as an exten the results of this type of usities. So far teresting but type of use have been Research has tended to indicate that, in. general, the computer is "as good as" Brebner, 1980). Much of this worth and the software being used and the tendency to use it in a lock-step format. Although the students can progress at their own computer presents the material. Most advantages seem to come from the comrepeat endlessly patience, its ability tiveness to students. It is likely that boredom with using the computer for learning will set in much the same way that the flashiest video game pales after VOLUME 13, NUMBER 4, 1984 CANADIAN JOURNAL OF EDUCATIONAL COMMUNICATION
This is not to suggest that the compute does not offer potential for improving technological presentation devices such as video tape or disk recorders, the compor providing and excellent possibilities stimuli and again bringing the learn close to the "real" world. When com( (t) 作 discovered in the many experiments ndertaken with large computers over the past decade, having a computer useful than having it deliver the

The third type of application of com-
puters in schools is their use as personal learning tools. Here the emphasis is changed, with the computer becoming ool that the student uses to explore the world and manage activities. The com used as a word processor or to creativity if be used to access information stored locally in the school or at remote sites and Wallable through communications networks. This places a very powerful cffers an exciting potential for increasing Thisty. of use also suggests the possibility of viewing the computer as a ticular maintains that this should be the principal means of using the computer.
He offers the computer and the LOGO and problem solving that will dramatical. an posed benefits from using, the sup uch as LOGO are based almost entirely on anecdotal evidences or on Papert's hat problem solving and thinking taught the computer translates to other tasks.

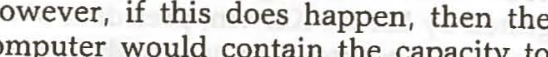
radically change the way we teach.

Thus, we find there are three main uses computers in schools: teaching about pumputers, the instructional use of compersonal learning tool. The first arises as a changes in the workplace, the second ut of a desire to make teaching more efficient and the third out of a desire to pro- 
vide the student with a potent personal tool for learning and problem solving. In ment and administrative uses that the computer is increasingly performing in schools.

Whatever uses of the computer we proach to using it is a rational one and based on sound educational practice, not fads. This requires a way of determining propriate. The following are generalized guidelines that should be followed planning programs using the computer.
The use of a computer in education The use of a

appropriate if:

tage;
2. Its use is financially possible

3. Teachers who are interested and

trained are available;

4. Its role in the program is planned and well defined

Relevant software is available and of

Policy Issues

The application of computers to education raises a number of important issues.
Some come from the nature of the changes in society attributable to the use of computers and some from their specific application in schools. The following is not an attempt to provide
answers but rather to raise questions. In answers but rather to raise questions. In
most cases the answers are neither simple most cases the answers are neither simple puters and observed their effect on society that the answers will become clear. Work and school: There is no denying the pressing need to train and retrain workers and managers for the variety of society. Howevr, it must be remembered that while the demand for highly trained individuals will rise, the new technologies may also cause structural
unemployment, job losses, and create unemployment, job losses, and create
more low skilled jobs (Opportunities. 1984 and Learning. .., 1984). As suggested by Larkin Kerwin, president of the National Research Council (Matas, 1983), it may be more important for schools to turn out graduates adaptable to change
rather than ones with overly specialized skills. As a result, the need for retraining ing opportunities will assume increasing importan

Curriculum changes: The study of computers is now becoming common- place. However, this should not lead us to plopt an unecessarily narrow approach ance, is not a skill likely to be the future (Matas, 1983]. More important is teaching students how to apply the power of a computer to solve problems and about the potential social pects of information technology. The mpact of computer studies of Study is mandatory, what is being left out of the curriculum to accommodate it? The importance of lifelong learning and the need for schools to turn out graduates adaptable to change suggests it may be necessary to rethink the purpose of vocapossibilities and does not unnecessarily narrow the options of the student.

Instructional uses: The use of any technology must be judged to ensure its tion that is applied to other educational materials is needed to guarantee that computer software is suitable, free of bias and of high quality. By the same token he use of the computer should encourage imply be based on rigid performanc objectives (Smith 1983) Care must also be aken to ensure that skills being learned at the computer are or can be generalized to ther areas. Equary ovidence is of computers arise early biases in the use Fisher, 1984). In many instances this eems to result from an unconscious reinforcement of male uses of the compute and from software that emphasizes games to male students. There is also a growing concern that children from economically disadvantaged families may not have access to computers, either in the home or the school. It is important to make certai that they, as well as female students, are computers and other technolo use devices. The use of computers in education should not result in an elite whether it be because of the cost of the technolog/ or the type of student that we encourage

Teacher training: While our schools with the new technologies, the teachers by and large, were trained before many of the technologies even existed. Probably the most critical factor in the use of echnology in education is teachers train- ed and comfortable with that technology Computers are currently being used by schools will not take place until the jority of teachers have had training in the use of computers in education. It is im portant to remember that changes based prechnology originate in on made intelligible and given, must be made intelligible and given values in 1981). We see the effects of this in the school where some students may know more about the computer than thei teachers. This presents a particular prob lem for mounting good staff developmen include fear of technology, resistance to change, anxiety over possible job loss and the increasing average age of teachers. Costs of technology: The costs of in
roducing new technology to the class room should not be underestimated. Mo of computer time available to students one half hour per day. To do so at present costs would require at least $2 \%$ of a schoo district's total educational budget or about $\$ 50$ per student per year (Mourmuch until one considers that the experditures on all instructional supplies used in education - books, films, etc. amount to only $2.5 \%$ of the total budget already evidence that expenditures on computers and computer software are
diverting funds from tradition materials. This would not be so worrying if these were one time expenditures however, the rapid developments in com puter technology and the need for new are not.

Social impacts: Finally, the social impacts of the new information technology
should not be overlooked. They are lready being felt in the workplace. Fo instance, "In Short Supply", the report (hesed the technology could result in an unemploy ment rate of up to $35 \%$ for female clerical workers by 1990. Some of this could be offset by the demand for technical and displaced workers have access to the training necessary to fill the positions. is readily apparent that changing skill requirements will place more importance pecial issues to be addresties. Other special issues to be addressed includ and the effect of increased leisure time (Mol

Conclusions:

The central questions facing us are how the educational system will make use of what is their best use. Information itself is he natural resource that supplements energy. We are in the midst of a tremendous experiment based on exploring new ways of storing, sharing and using information through computers, information
networking, satellites and other com munications devices. There is no doub that the rapidly expanding new communications technologies have helped bring about an information revolution
worldwide. What is important, however, worldwide. What is important, however,
is that these new technologies not be viewed in isolation from other resource is a danger in an over-reliance on any one medium. There is simply too much infornation in too much variety to select only e source of transfer

importance of rant that we not forge Both research and experience have proven that learning is enhanced when the earner is directly involved with the ctual object of consideration. The comuter is not a substitute for physical commodate the diverse learning styles of individua

The classroom and the school should be Thurce centres, not just computer cen-
es. In order to provide for different lear. styles and interests, our schools nust continue to provide a full range of resources, including books, periodicals, media materials such as filmstrips and puters. We must enhance learning by providing opportunities for student exprereinforce through fied arts, motivate and outside into the chips and bring the resources, both technological and no should perme te educatin and physica The permeate education

Thy but it cannot do the jobas a role to must find the appropriate uses for the computer and help prepare our student lifelong lorning but for the prospect of may be used to change the way we and they may become personal learning tools for students, but it is still too early tell for certain. The challenge for us is to learn whether or not the marriage be schools is one which will endure make a better system. Indications are that it will, but that many of the details still remain to be worked out.

\section{EFERENCES}

(cker, H.J. "How schools use microLearning. September 41-44.

ducation statistics," Service Bulletin. 16. 4, No. 9, December, 1982, pp.

her, G. "Access to computers," The Computing Teacher. April, 1984, pp. 24-27. puter Assisted Instruction i Pchools: Achievements, Presen
Developments and Projections for the Future. Alberta Education: Edmonton, 1980. S. Bconomic Council of Canada

Dolata, G. "Equal time for women,' Discover. January, 1984, pp. 24-27. Panel on Skill Development Leave: Ottawa, 1984.

Information Society Society: tas, R. "Schoo

pecialists The Globe and Mail. April 20, 1983.

Science. May 1984, "Computer worship," oursund, D. "The two-percent solution," The Computing Teacher. March, 1984, pp. 3-5.

"Opportunities for high-tech jobs limand Mail. April 12,1985

New York, 1980 Fourth chools? Proceedings of the tructium on InReserch Council: Ottawa Natonal

Sharon, D. Communications and Information Technologies in Canadian Elemantary and Secondary ith S. Address to Computers in Education. Science
Council of Canada: Ottawa, 1983 . olcott, H.F. "Is there life after technology? Some lessons in change," 1981, pp. 24-28. 